\title{
On the Synthesis of Molybdenum Nanoparticles under Reducing Conditions in Ionic Liquids
}

\author{
Ayi A. Ayi, ${ }^{1}$ Chinyere A. Anyama, ${ }^{1}$ and Varsha Khare $^{2,3}$ \\ ${ }^{1}$ Materials Chemistry Unit, Department of Pure and Applied Chemistry, University of Calabar, PMB 1115, Calabar, Nigeria \\ ${ }^{2}$ Institute of Chemistry, University of Potsdam, Karl-Liebknecht-Straße 24-25, Building 26, 14476 Golm, Germany \\ ${ }^{3}$ Max Planck Institute of Colloids and Interfaces, 14476 Golm, Germany
}

Correspondence should be addressed to Ayi A. Ayi; ayiayi72@gmail.com

Received 26 June 2015; Accepted 18 August 2015

Academic Editor: Huan-Tsung Chang

Copyright (C) 2015 Ayi A. Ayi et al. This is an open access article distributed under the Creative Commons Attribution License, which permits unrestricted use, distribution, and reproduction in any medium, provided the original work is properly cited.

\begin{abstract}
We report on attempts to synthesize Mo nanoparticles under reducing conditions in ionic liquids (ILs). Ionic liquids were based on the 1-ethyl-3-methylimidazolium or 1-butyl-3-methylimidazolium (Emim and Bmim, resp.) cations and the dicyanamide $\mathrm{N}(\mathrm{CN})_{2}$, triflate (OTf), bis(trifluoromethylsulfonyl)imide- $\left(\mathrm{NTf}_{2}\right)$, tetrafluoroborate $\left(\mathrm{BF}_{4}\right)$, ethyl sulfate (ES), and methylsulfonate (MS) anions. $\left(\mathrm{NH}_{4}\right)_{6} \mathrm{Mo}_{7} \mathrm{O}_{24} * 4 \mathrm{H}_{2} \mathrm{O}$ and $\mathrm{NaBH}_{4}$ were reacted in a set of imidazolium ionic liquids (ILs) at $180^{\circ} \mathrm{C}$ to evaluate the potential of the ILs for stabilization of metallic Mo nanoparticles. XRD and TEM reveal a strong influence of the IL anion on the particle sizes, shapes, and crystal structures. The influence of the IL cation and the reaction temperature is much less pronounced.
\end{abstract}

\section{Introduction}

The recent interest in the synthesis and characterization of nanomaterials is due to diverse areas of applications, including catalysis, sensing, and electrochemistry [1-3]. By now, it is well established that the size, shape, orientation, and chemical composition of the nanoparticles have a tremendous impact on their performance [3-6]. There is thus a need to control these parameters for efficient operation of a device or device component. While there are many protocols available for the synthesis of metallic nanoparticles $[6,7]$, there is a need to further elaborate protocols for the synthesis and stabilization of less stable metal particles such as titanium and molybdenum, because these could be interesting for a variety of applications, yet they have not been made via conventional approaches in aqueous or organic solution. Consequently, ionic liquids have been investigated as candidates for the synthesis of many metal nanoparticles [7], including titanium and molybdenum nanoparticles, because ILs have in the recent past been established as useful media for the synthesis of a wide variety of inorganic materials [8-12]. While the synthesis of titanium nanoparticles, even from ILs, has remained elusive $[13,14]$, the synthesis of molybdenum nanoparticles in ILs has been reported [15]. The approach is based on the thermal decomposition of metal carbonyls, which has enabled the synthesis of many metal nanoparticles [15-18].

The current study thus focuses on attempts at synthesizing Mo nanoparticles in ILs via chemical reduction, starting from conventional precursors such as ammonium molybdate tetrahydrate $\left(\mathrm{NH}_{4}\right)_{6} \mathrm{Mo}_{7} \mathrm{O}_{24} \cdot 4 \mathrm{H}_{2} \mathrm{O}$ and sodium borohydride $\mathrm{NaBH}_{4}$. In principle, there are a virtually unlimited number of ILs available, but, for this present investigation, the focus is on ILs based on 1-ethyl-3-methylimidazolium or 1-butyl-3-methylimidazolium (Emim and Bmim, resp.) cations and the dicyanamide $\mathrm{N}(\mathrm{CN})_{2}$, triflate (TfO), bis(trifluoromethylsulfonyl)imide- $\mathrm{NTf}_{2}$, tetrafluoroborate $\left(\mathrm{BF}_{4}\right)$, methylsulfonate (MS), and ethyl sulfate (ES) anions. These ILs are available in good qualities and there is a large dataset on their chemical and physical properties available from numerous studies in the literature [19-23]. They thus provide a good starting point for the evaluation of the potential of ILs for Mo nanoparticle synthesis and stabilization.

\section{Experimental Section}

2.1. Materials. All ILs were obtained from Iolitec. $\left(\mathrm{NH}_{4}\right)_{6} \mathrm{Mo}_{7} \mathrm{O}_{24} \cdot 4 \mathrm{H}_{2} \mathrm{O}$ and $\mathrm{NaBH}_{4}$ were obtained from Merck. All chemicals were used as received. 


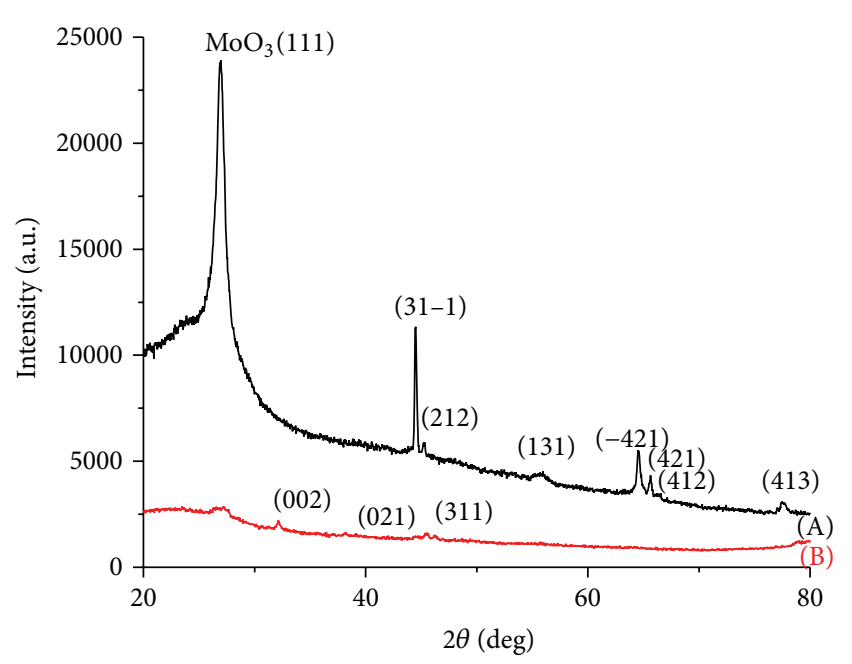

(a)

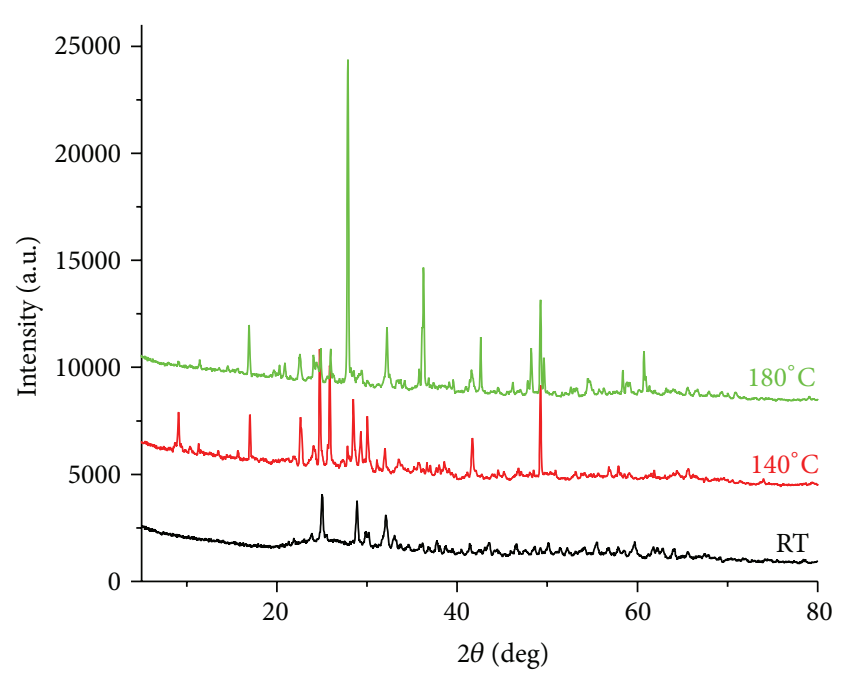

(c)

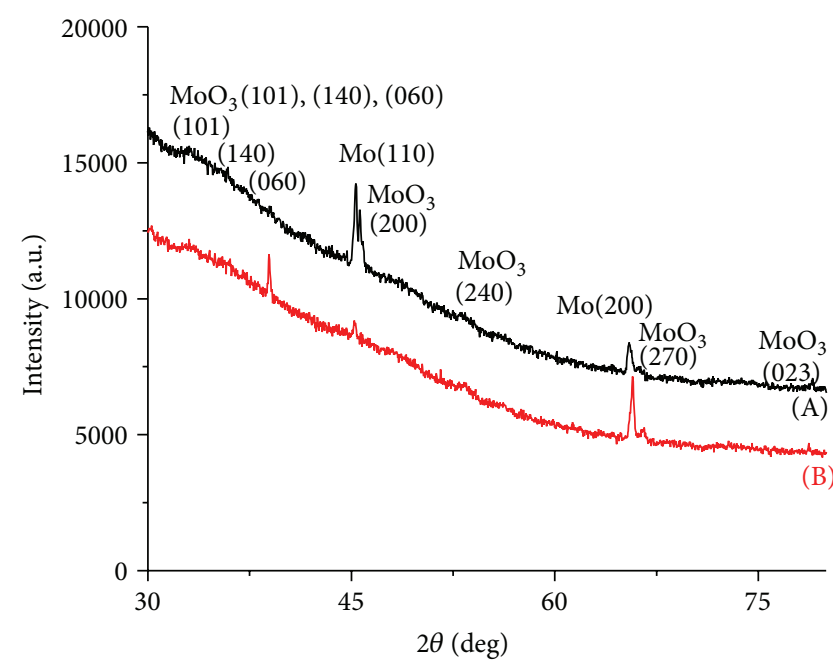

(b)

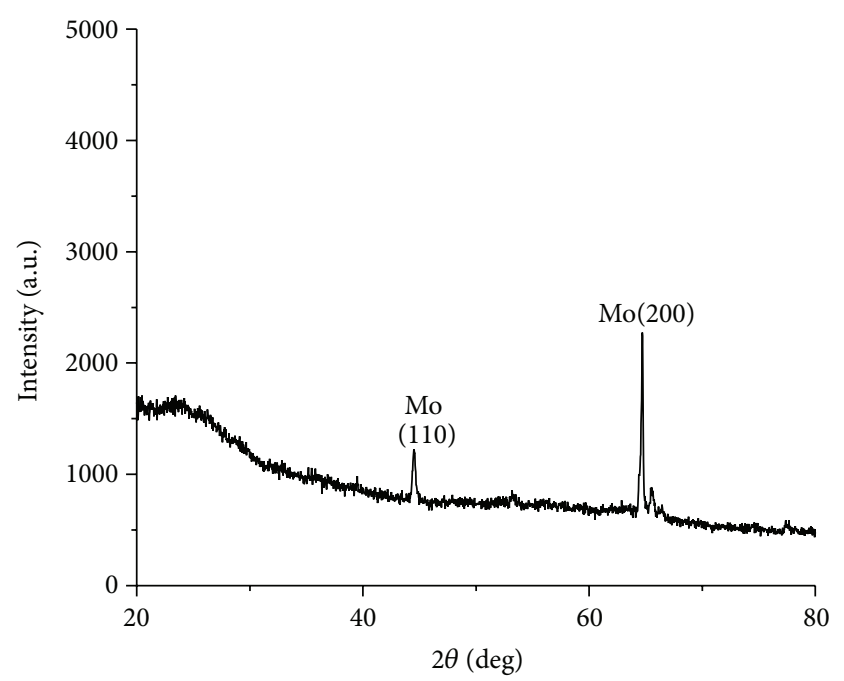

(d)

FIGURE 1: Representative XRD patterns of products from different ILs: (a) N(CN) $)_{2}$, (b) OTf, (c) MS, and (d) ES.

2.2. Nanoparticle Synthesis. In a typical synthesis, $\left(\mathrm{NH}_{4}\right)_{6} \mathrm{Mo}_{7} \mathrm{O}_{24} \cdot 4 \mathrm{H}_{2} \mathrm{O}(30.896 \mathrm{mg}, 0.025 \mathrm{mmol})$ was dispersed in $[\mathrm{Emim}]\left[\mathrm{N}(\mathrm{CN})_{2}\right](1031.3 \mathrm{mg}, 5 \mathrm{mmol})$ and sonicated for $10 \mathrm{~min}$. before introducing $\mathrm{NaBH}_{4}(3.78 \mathrm{mg}$, $1 \mathrm{mmol})$. The resulting colorless solution with molar composition 10IL : $5\left(\mathrm{NH}_{4}\right)_{6} \mathrm{Mo}_{7} \mathrm{O}_{24} \cdot 4 \mathrm{H}_{2} \mathrm{O}: 2 \mathrm{NaBH}_{4}$ was heated to $180^{\circ} \mathrm{C}$ for $24 \mathrm{~h}$. The product, a dark red colloidal precipitate, was isolated by centrifugation.

2.3. Characterization. X-ray diffraction (XRD) was done on an ENRAF Nonius FR 590 diffractometer with a $\mathrm{Cu} \mathrm{K}_{\alpha} \mathrm{X}$ ray tube fitted with an Inel CPS 120 hemispherical detector ranging from 1 to 120 degrees $2 \theta$. From the intensity data of the XRD peaks, the fraction of metallic molybdenum $\left(f_{\mathrm{Mo}}\right)$ was calculated using the equation:

$$
f_{\mathrm{Mo}}=\frac{I_{\mathrm{Mo}(110)}}{\left[I_{\mathrm{Mo}(110)}+I_{\mathrm{MoO}_{3}(200)}\right]},
$$

where $I_{(110)}$ is the intensity of (110) metallic molybdenum reflection and $I_{(200)}$ is the intensity of (200) $\mathrm{MoO}_{3}$. FT-IR spectra on solid samples were recorded on $\mathrm{KBr}$ pellets on a Thermo Nicolet Nexus 670 spectrometer between 400 and $4000 \mathrm{~cm}^{-1}$ with a resolution of $4 \mathrm{~cm}^{-1}$. UV/Vis spectra were recorded on particle dispersions in ILs on an Agilent 8453 spectrometer in $10 \mathrm{~mm}$ quartz cuvettes. UV-Vis spectra were collected both from the dispersions in ILs and from samples redispersed in ethanol. All measurements were done at room temperature. Transmission electron microscopy (TEM) images were acquired on a Zeiss EM 912 at an acceleration voltage of $120 \mathrm{kV}$. One droplet of the suspension was applied to a 400 mesh carbon-coated copper grid and left to dry in air. Scanning electron microscopy (SEM) was done on a LEO 1550 Gemini operated at $20 \mathrm{kV}$.

\section{Results and Discussion}

Figure 1 shows selected XRD patterns of particles obtained from the different ILs at $180^{\circ} \mathrm{C}$ (for $\mathrm{N}(\mathrm{CN})_{2}$, OTf, and ES) and at 30,140 , and $180^{\circ} \mathrm{C}$ for MS. XRD analysis shows that the Emim or Bmim cation is of minor importance in product 
TABLE 1: Products obtained from ILs.

\begin{tabular}{|c|c|c|c|c|c|}
\hline IL cation & IL anion & $\begin{array}{l}\text { Color of the } \\
\text { precipitate }\end{array}$ & Products (JCPDS) & Fraction $^{\mathrm{A}}$ & Crystal system \\
\hline$[\mathrm{Bmim}]$ & {$\left[\mathrm{BF}_{4}\right]$} & Light yellow & $\mathrm{Mo}_{4} \mathrm{O}_{11}(65-2473)$ & & Orthorhombic \\
\hline $\begin{array}{l}{[\mathrm{Bmim}]} \\
{[\mathrm{Emim}]} \\
\end{array}$ & $\mathrm{N}(\mathrm{CN})_{2}$ & Dark red & $\mathrm{MoO}_{3}(47-1081)$ & & Monoclinic \\
\hline $\begin{array}{l}\text { Bmim }] \\
{[\text { Emim }]} \\
\end{array}$ & {$[\mathrm{TfO}]$} & $\begin{array}{c}\text { Brown-olive } \\
\text { green }\end{array}$ & $\begin{array}{c}\mathrm{Mo}(42-1120) \\
\mathrm{MoO}_{3}(65-2421)\end{array}$ & $\begin{array}{r}59 \% \\
41 \% \\
\end{array}$ & $\begin{array}{c}\text { Cubic } \\
\text { Orthorhombic }\end{array}$ \\
\hline $\begin{array}{l}\text { [Bmim }] \\
{[\text { Emim }]} \\
\end{array}$ & {$\left[\mathrm{Tf}_{2} \mathrm{~N}\right]$} & Brown & $\begin{array}{c}\mathrm{MoO}_{3}(65-2421) \\
\mathrm{Mo}_{17} \mathrm{O}_{47}(13-0345)\end{array}$ & & Orthorhombic \\
\hline [Emim] & MS & Brown & $\mathrm{Mo}_{4} \mathrm{O}_{11}(65-2473)$ & & Orthorhombic \\
\hline [Emim] & ES & Dark red & Mo (42-1120) & & Cubic \\
\hline
\end{tabular}

A: for calculation of fractions see experimental part. Unless specified otherwise, the samples are single phase.

TABLE 2: Particle morphology and particle sizes versus IL composition.

\begin{tabular}{|c|c|c|c|}
\hline IL cation & IL anion & Shape & Size \\
\hline [Bmim] & {$\left[\mathrm{BF}_{4}\right]$} & $\begin{array}{l}\text { (1) Rounded, "sintered-looking" } \\
\text { (2) Spherical }\end{array}$ & $\begin{array}{l}100-300 \mathrm{~nm} \\
5-10 \mathrm{~nm}\end{array}$ \\
\hline $\begin{array}{l}{[\mathrm{Bmim}]} \\
{[\mathrm{Emim}]}\end{array}$ & $\mathrm{N}(\mathrm{CN})_{2}$ & $\begin{array}{l}\text { (1) Wires/fibers } \\
\text { (2) Spherical }\end{array}$ & $\begin{array}{l}\text { Microns } \times \text { ca. } 5 \mathrm{~nm} \\
5-10 \mathrm{~nm}\end{array}$ \\
\hline $\begin{array}{l}{[\mathrm{Bmim}]} \\
{[\mathrm{Emim}]}\end{array}$ & {$[\mathrm{TfO}]$} & "Raspberry" & $10-50 \mathrm{~nm}$ \\
\hline $\begin{array}{l}{[\mathrm{Bmim}]} \\
{[\mathrm{Emim}]}\end{array}$ & {$\left[\mathrm{Tf}_{2} \mathrm{~N}\right]$} & $\begin{array}{l}\text { (1) Well-developed crystals, strongly aggregated } \\
\text { (2) Spherical (presumably IL droplets with inorganic shell) } \\
\text { (3) Spherical }\end{array}$ & $\begin{array}{l}10 \mathrm{~s} \text { of microns } \\
\text { Microns } \\
\text { Below } 10 \mathrm{~nm} \\
\end{array}$ \\
\hline [Emim] & MS & $\begin{array}{l}\text { (1) Plate/rod } \\
\text { (2) Rod or cuboid } \\
\text { (3) "Fluffy" rounded } \\
\text { (4) Spherical }\end{array}$ & $\begin{array}{l}10 \mathrm{~s} \text { of microns } \\
\text { Ca. } 100 \mathrm{~nm} \\
\text { Ca. } 10 \mathrm{~nm} \\
\text { Below } 10 \mathrm{~nm}\end{array}$ \\
\hline [Emim] & ES & Spherical & $5-25 \mathrm{~nm}$ \\
\hline
\end{tabular}

formation. In contrast, the anion plays a significant role, as a clear influence of the nature of the anion on the product is observed, as shown in Table 1 . In $\left[\mathrm{N}(\mathrm{CN})_{2}\right]$ ILs, the most representative reflections of $\mathrm{MoO}_{3}$ (JCPDS: 47-1081) were indexed in monoclinic crystal system (space group P2 $1 / \mathrm{c}(14)$ ) with the following cell parameters: $a=7.118, b=5.366$, $c=5.568 \AA$ A,$\beta=91.99^{\circ}$, Vol. $=212.5 \AA^{3}, Z=4$, and density $=$ $4.4991 \mathrm{gcm}^{-3}$. The average mean diameter of $53.8 \mathrm{~nm}$ was calculated with the help of Debye-Scherrer equation from Full Width at Half-Maximum (FWHM) of (111), (-311), (160), (-421), (330), and (413) planes. In contrast, the reductions in [TfO] and $\left[\mathrm{Tf}_{2} \mathrm{~N}\right]$ ILs lead to $\mathrm{MoO}_{3}$ determined to be orthorhombic, space group Pbnm (62) with the cell dimen-

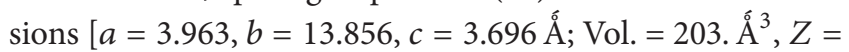
$\left.4, \rho=4.7096 \mathrm{gcm}^{-1}\right]$ corresponding to $\mathrm{MoO}_{3}$ (JCPDS: 350609). [TfO] also leads to Mo particles, which is not observed with $\left[\mathrm{Tf}_{2} \mathrm{~N}\right] .\left[\mathrm{BF}_{4}\right]$ and $[\mathrm{MS}]$ ILs yield $\mathrm{Mo}_{4} \mathrm{O}_{11}$ and the [ES] anion favors the formation of Mo particles. XRD thus clearly shows that the IL anions (as has been shown in many other studies) [24] are the key parameters in the mineralization process.

Figures 2 and 3 show representative scanning electron microscopy (SEM) and transmission electron microscopy (TEM) images, respectively, of the products obtained in different ILs. Table 2 summarizes the morphologies and particle sizes versus the IL chemistry. As already suggested by the XRD data (Figure 1), there are no differences between the [Emim] and [Bmim] cations on the particle sizes and morphologies. There are like in XRD dramatic effects of the IL anions on these parameters. ILs with the $\left[\mathrm{BF}_{4}\right]$ anion show two types of particles, large, rounded particles with sizes in few $100 \mathrm{~nm}$ range, and very small spherical particles with diameters below $10 \mathrm{~nm}$. The larger particles are reminiscent of TEM images of sintered ceramics; that is, they typically do not show up as individual particles. Rather, they are connected, exhibit pores between the particles, and exhibit visible grain boundaries between individual connected particles. In contrast, the small particles are present as individual objects.

ILs with $[\mathrm{MS}]$ and $\left[\mathrm{N}(\mathrm{Tf})_{2}\right]$ anions lead to an even more heterogeneous range of products. $\left[\mathrm{N}(\mathrm{Tf})_{2}\right]$ anion lead to (1) large crystals with well-developed faces that typically are present in the form of tens of micrometer-sized strongly aggregated assemblies, (2) spherical objects with diameters in the micrometer range that appear to consist of IL droplets surrounded by an inorganic shell, and (3) isolated spherical particles with a diameter of a few nanometers. Similarly, the [MS] anion leads to (1) large, plate or rod like particles in the tens of micrometer size range, (2) much smaller 

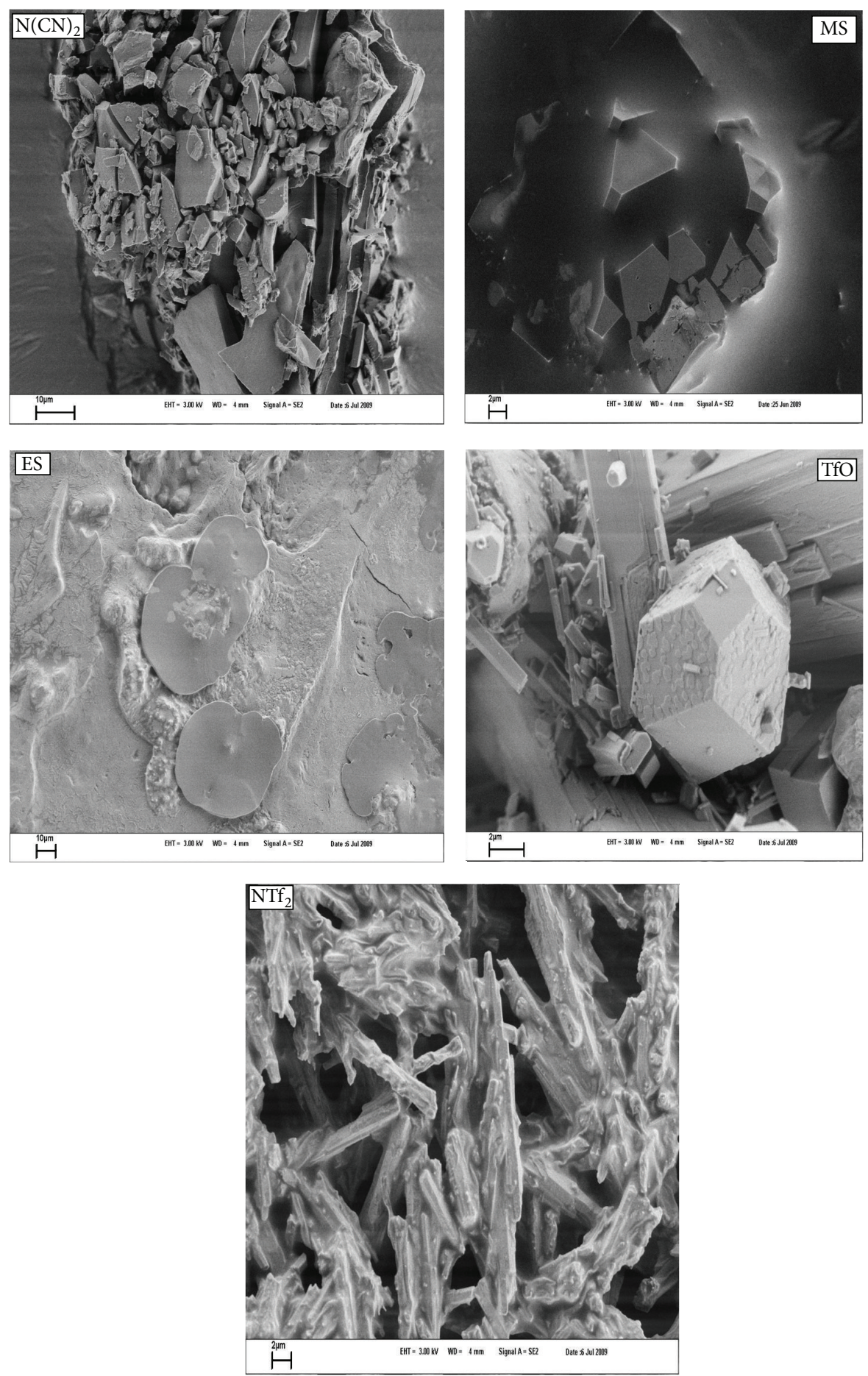

FIGURE 2: SEM images of representative precipitates obtained from different ILs.

rod like or cuboid features with sizes in the $100 \mathrm{~nm}$ range, (3) roughly spherical particles, but fluffy looking particles with a size in the $10 \mathrm{~nm}$ range, and finally (4) spherical nanoparticles with diameters of a few nanometers. In short, [MS] and $\left[\mathrm{NTf}_{2}\right]$ ILs lead to a large variety of particles, each of which has specific size range from tens of micrometers to tens of nanometers. The samples grown in $\left[\mathrm{N}(\mathrm{CN})_{2}\right]$ are difficult to analyze in the TEM. This is mostly due to the poor contrast. Nevertheless, TEM shows that, only in this IL, fiber like entities with a length of few $100 \mathrm{~nm}$ coexist with, again, spherical nanoparticles with a diameter of a few nanometers. This is consistent with the observation that, only in this IL, the viscosity shows a dramatic increase after the reaction is terminated, a phenomenon indicating the formation of a gel rather than a fluid phase containing discrete (nano)particles. 

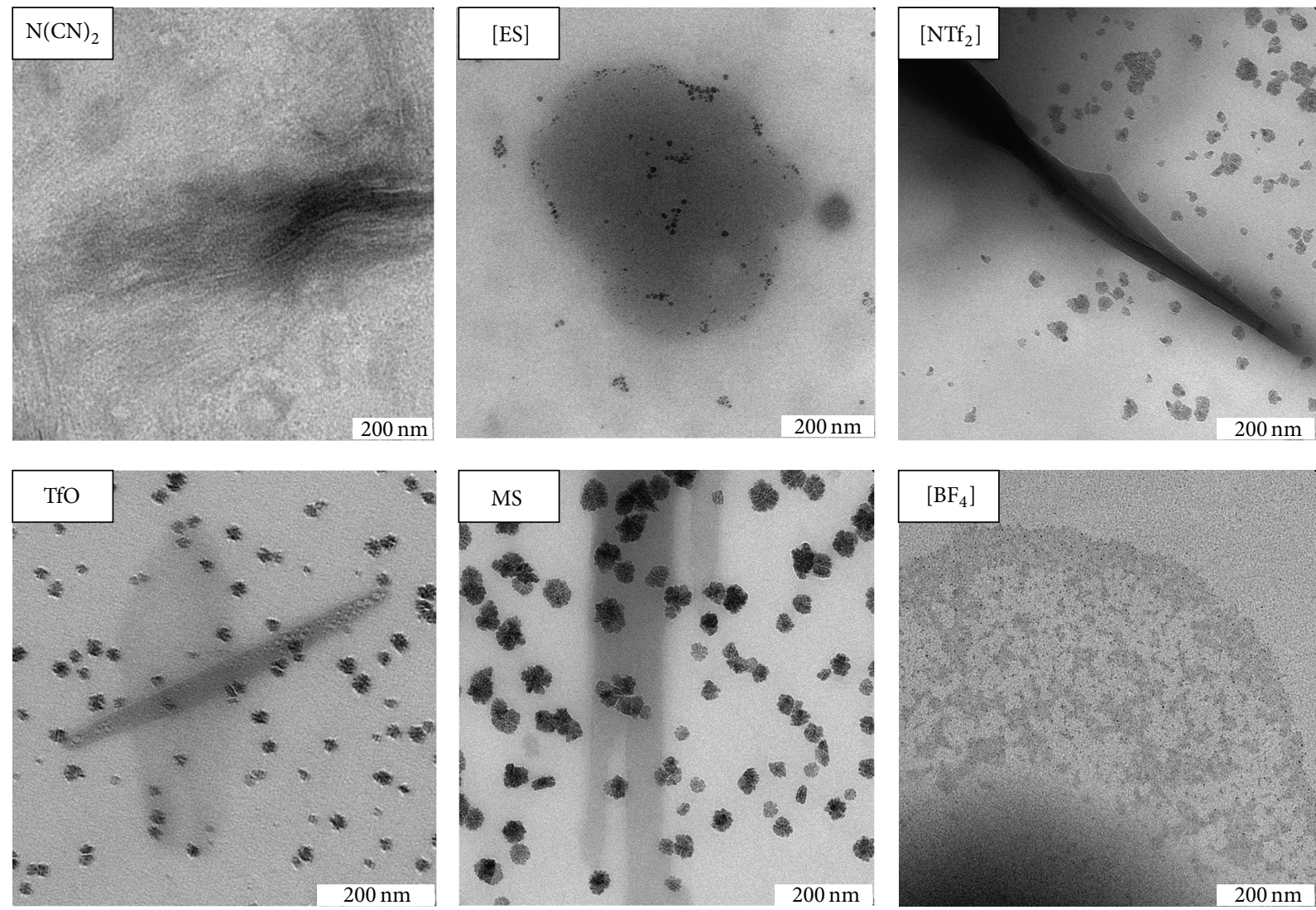

FIGURE 3: TEM images of representative precipitates obtained from different ILs.

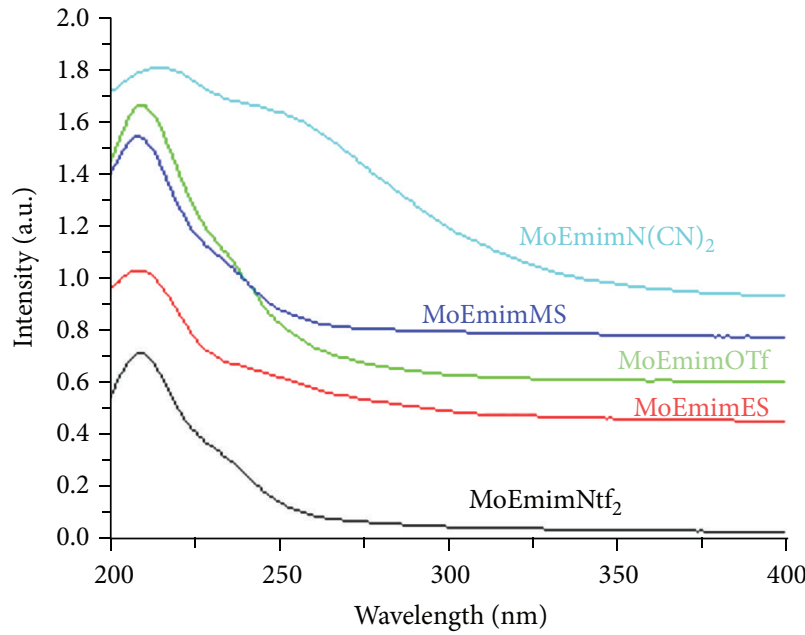

(a)

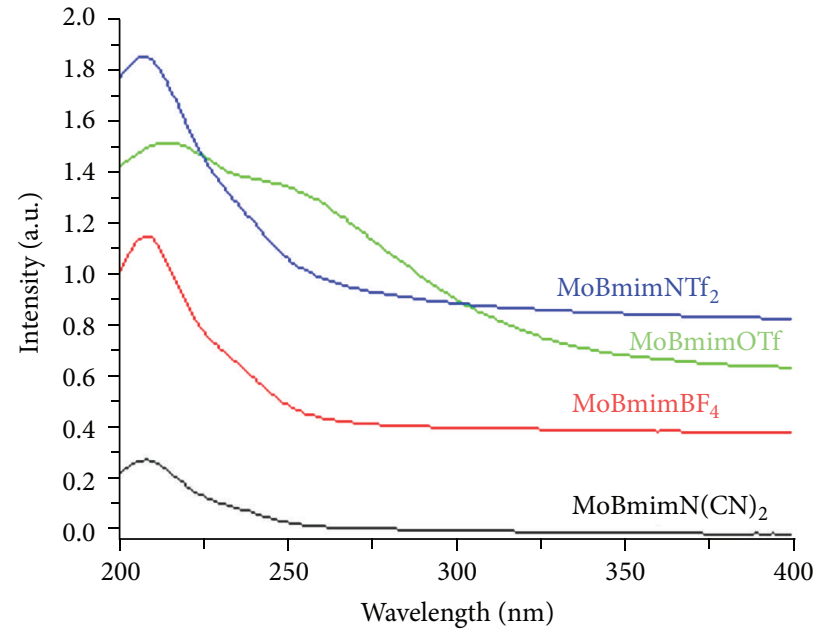

(b)

FIGURE 4: UV-Vis spectra of representative samples: (a) 1-ethyl-3-methylimidazolium-based or (b) 1-butyl-3-methylimidazolium-based ILs.

In contrast to all examples described so far, the samples grown in ILs based on the [TfO] and the [ES] anions are rather homogeneous yielding particles with a roughly spherical shape and a diameter between 10 and $50 \mathrm{~nm}$ ([TfO] anion) and 5 and $25 \mathrm{~nm}$ ([ES] anion). The particles grown in [TfO] have a raspberry-like structure, inasmuch as they appear to be composed of smaller particles of a few $\mathrm{nm}$ in diameter. In contrast, the particles grown in [ES] based ILs are solid spheres in the TEM, similar to the other small spheres described before.

Figure 4 shows representative UV/Vis spectra of nanoparticles redispersed in ethanol. Although nanoparticles are well known for their specific absorption characteristics, the spectra of samples under investigation show signals that 


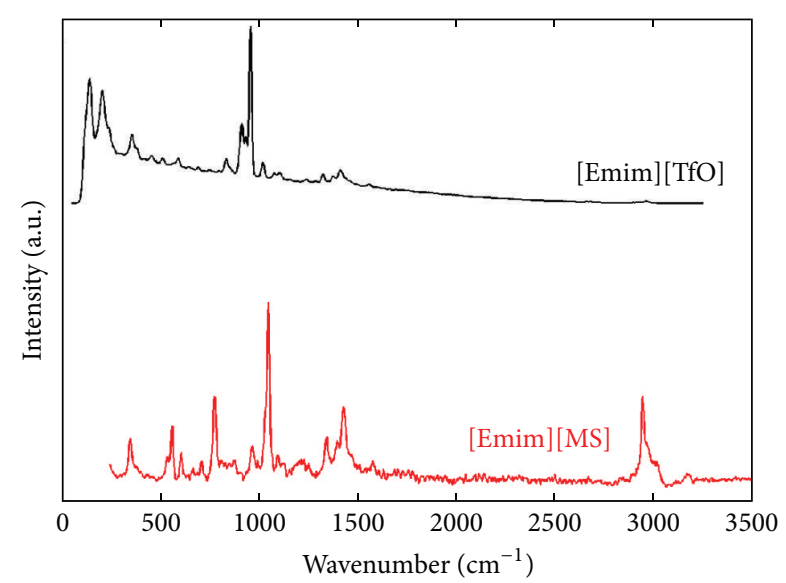

FIGURE 5: IR and Raman spectra of selected samples after isolation, washing, and drying.

can be assigned to the ILs only. This suggests that (1) there are only a few dispersed particles present and/or (2) that the particles still contain a significant amount of IL, similar to an earlier study, $[14,24]$ which can desorb into the ethanol as the dispersions were prepared from the isolated nanoparticle powders.

Figure 5 shows representative IR and Raman spectra of some samples. The stretching vibration in the region $3200-2900 \mathrm{~cm}^{-1}$ is assigned to the imidazolium C-H mode. The in-plane ring mode is observed in the region 1600$1500 \mathrm{~cm}^{-1}$. The aliphatic bending modes are observed in the region $1300-1050 \mathrm{~cm}^{-1}$. Complementary Raman spectra show bands at $202,352 \mathrm{~cm}^{-1}$ and in the region $830-1100 \mathrm{~cm}^{-1}$ corresponding to $\mathrm{Mo}-\mathrm{O}$ and $\mathrm{Mo}=\mathrm{O}$ vibrations.

All of the ILs used in this present study have the 1-ethyl-3methylimidazolium or 1-butyl-3-methylimidazolium cation, but the anions are $\mathrm{N}(\mathrm{CN})_{2}$, TfO, MS, $\mathrm{ES}, \mathrm{BF}_{4}$, and $\mathrm{NTf}_{2}$. It is worth noting that the particles grown in ILs with anions containing fluoroalkyl groups are well-developed crystals and larger in size than those grown in nonfluorinated anion. The particles size also correlate with the molar volume of the anion. We observed a size increase in the nanoparticles grown in ILs with increasing molar volume of the anion. There is a favorable interaction between the metal salt and the fluoroalkyl substituents on the anion leading to increasing solubility of the metal salt in these ILs and consequently faster nucleation and growth. It has been postulated that metal nanoparticles are stabilized in the ILs by the formation of protective anion and the cation layers around them in a core-shell system [25, 26]. Redel et al., 2008 [15, 16], have suggested that the thickness of the stabilizing shells around an MNP depends on the IL molecular ion volumes. According to the DLVO (Derjaguin-Landau-Verwey-Overbeek) theory [27], ILs provide an electrostatic protection in the form of protective shell for MNPs so that no extra stabilizing molecules are needed. In this type of stabilization, the anions and cations from the ILs which are in the colloidal dispersion associate with the nanoparticles leading to the formation of electrical double layer. The present study uses ionic liquids as a solvent and as a stabilizing agent in the nanoparticles synthesis.

\section{Conclusions}

In summary, stable Mo and molybdenum oxide nano- and microparticles have been synthesized in ILs with a variety of anions under reducing conditions. Most notably and in agreement with literature, XRD and TEM reveal a strong influence of the IL anion on the particle sizes, shapes, and crystal structures. The influence of the IL cation and the reaction temperature is much less pronounced. The experimental approach is less efficient than a method reported by Janiak and coworkers [17, 18], because it is much more dependent on the IL/molybdenum salt precursor combination but is possibly easier to scale up, as the molybdenum salt used here $\left(\mathrm{NH}_{4}\right)_{6} \mathrm{Mo}_{7} \mathrm{O}_{24} * 4 \mathrm{H}_{2} \mathrm{O}$ is essentially nontoxic, commercially available, and easy to handle. Although there is thus a need to better understand the nucleation and growth process and to further optimize the synthesis protocol, our approach presents a suitable strategy towards the controlled synthesis of molybdenum nanoparticles with a reasonable particle size distribution using the $\left(\mathrm{NH}_{4}\right)_{6} \mathrm{Mo}_{7} \mathrm{O}_{24} * 4 \mathrm{H}_{2} \mathrm{O} /[\mathrm{Emim}][\mathrm{ES}]$ pair.

\section{Conflict of Interests}

The authors declare that there is no conflict of interests regarding the publication of this paper.

\section{Acknowledgments}

The authors thank A. Taubert, K. Bleek, R. Göbel, and M. Junginger for useful discussions and help in the laboratory and R. Pitschke and H. Runge for help with SEM/TEM experiments. The University of Potsdam and the Max Planck Institute of Colloids and Interfaces are gratefully acknowledged for hosting Ayi A. Ayi as a DAAD Research Fellow.

\section{References}

[1] F. Caruso, Colloids and Colloid Assemblies, Wiley-VCH, Weinheim, Germany, 2004.

[2] H. E. Bergna and W. O. Roberts, Colloidal Silica-Fundamentals and Applications, vol. 131 of Surfactant Science Series, Taylor \& Francis, Boca Raton, Fla, USA, 2006.

[3] M.-C. Daniel and D. Astruc, "Gold nanoparticles: assembly, supramolecular chemistry, quantum-size-related properties, and applications toward biology, catalysis, and nanotechnology," Chemical Reviews, vol. 104, no. 1, pp. 293-346, 2004.

[4] M. A. El-Sayed, "Some interesting properties of metals confined in time and nanometer space of different shapes," Accounts of Chemical Research, vol. 34, no. 4, pp. 257-264, 2001.

[5] A. Biswas, T. Wang, and A. S. Biris, "Single metal nanoparticle spectroscopy: optical characterization of individual nanosystems for biomedical applications," Nanoscale, vol. 2, no. 9, pp. 1560-1572, 2010

[6] N. Semagina and L. Kiwi-Minsker, "Recent advances in the liquid-phase synthesis of metal nanostructures with controlled 
shape and size for catalysis," Catalysis Reviews: Science and Engineering, vol. 51, no. 2, pp. 147-217, 2009.

[7] J. Dupont and J. D. Scholten, "On the structural and surface properties of transition-metal nanoparticles in ionic liquids," Chemical Society Reviews, vol. 39, no. 5, pp. 1780-1804, 2010.

[8] E. R. Parnham and R. E. Morris, "Ionothermal synthesis of zeolites, metal-organic frameworks, and inorganic-organic hybrids," Accounts of Chemical Research, vol. 40, no. 10, pp. 1005-1013, 2007.

[9] R. E. Morris, "Ionic liquids and microwaves-making zeolites for emerging applications," Angewandte Chemie International Edition, vol. 47, no. 3, pp. 442-444, 2008.

[10] A. Taubert, "Inorganic materials synthesis-a bright future for ionic liquids?" Acta Chimica Slovenica, vol. 52, no. 3, pp. 183186, 2005.

[11] A. Taubert and Z. Li, "Inorganic materials from ionic liquids," Dalton Transactions, no. 7, pp. 723-727, 2007.

[12] Z. Li, Z. Jia, Y. Luan, and T. Mu, "Ionic liquids for synthesis of inorganic nanomaterials," Current Opinion in Solid State and Materials Science, vol. 12, no. 1, pp. 1-8, 2008.

[13] F. Endres, S. Zein El Abedin, A. Y. Saad et al., "On the electrodeposition of titanium in ionic liquids," Physical Chemistry Chemical Physics, vol. 10, no. 16, pp. 2189-2199, 2008.

[14] A. A. Ayi, V. Khare, P. Strauch, J. Girard, K. M. Fromm, and A. Taubert, "On the chemical synthesis of titanium nanoparticles from ionic liquids," Monatshefte für Chemie, vol. 141, no. 12, pp. 1273-1278, 2010.

[15] E. Redel, R. Thomann, and C. Janiak, "Use of ionic liquids (ILs) for the IL-anion size-dependent formation of Cr, Mo and W nanoparticles from metal carbonyl $\mathrm{M}(\mathrm{CO})_{6}$ precursors," Chemical Communications, no. 15, pp. 1789-1791, 2008.

[16] E. Redel, R. Thomann, and C. Janiak, "First correlation of nanoparticle size-dependent formation with the ionic liquid anion molecular volume," Inorganic Chemistry, vol. 47, no. 1, pp. 14-16, 2008.

[17] J. Krämer, E. Redel, R. Thomann, and C. Janiak, "Use of ionic liquids for the synthesis of iron, ruthenium, and osmium nanoparticles from their metal carbonyl precursors," Organometallics, vol. 27, no. 9, pp. 1976-1978, 2008.

[18] C. Vollmer, E. Redel, K. Abu-Shandi et al., "Microwave irradiation for the facile synthesis of transition-metal nanoparticles (NPs) in ionic liquids (ILs) from metal-carbonyl precursors and $\mathrm{Ru}-, \mathrm{Rh}-$, and Ir-NP/IL dispersions as biphasic liquid-liquid hydrogenation nanocatalysts for cyclohexene," Chemistry, vol. 16, no. 12, pp. 3849-3858, 2010.

[19] R. D. Rogers and K. R. Seddon, Ionic Liquids: Industrial Applications for Green Chemistry, ACS Symposium Series 818, American Chemical Society, 2002.

[20] R. D. Rogers and K. R. Seddon, Ionic Liquids As Green Solvents: Progress and Prospects, ACS Symposium Series 856, American Chemical Society, Washington, DC, USA, 2003.

[21] R. D. Rogers and K. R. Seddon, Ionic Liquids IIIA: Fundamentals, Progress, Challenges, and Opportunities: Properties and Structure, ACS Symposium Series 901, American Chemical Society, 2005.

[22] P. Wasserscheid and T. Welton, Ionic Liquids in Synthesis, WileyVCH, Weinheim, Germany, 2007.

[23] B. Kirchner, Ionic Liquids, vol. 290 of Topics in Current Chemistry, Springer, New York, NY, USA, 2009.

[24] V. Khare, Z. Li, A. Mantion et al., "Strong anion effects on gold nanoparticle formation in ionic liquids," Journal of Materials Chemistry, vol. 20, no. 7, pp. 1332-1339, 2010.
[25] E. Redel, J. Krämer, R. Thomann, and C. Janiak, "Synthesis of $\mathrm{Co}, \mathrm{Rh}$ and Ir nanoparticles from metal carbonyls in ionic liquids and their use as biphasic liquid-liquid hydrogenation nanocatalysts for cyclohexene," Journal of Organometallic Chemistry, vol. 694, no. 7-8, pp. 1069-1075, 2009.

[26] J. Dupont, G. S. Fonseca, A. P. Umpierre, P. F. P. Fichtner, and S. R. Teixeira, "Transition-metal nanoparticles in imidazolium ionic liquids: recycable catalysts for biphasic hydrogenation reactions," Journal of the American Chemical Society, vol. 124, no. 16, pp. 4228-4229, 2002.

[27] E. J. W. Verwey and J. T. G. Overbeek, Theory of the Stability of Lyophobic Colloids, Dover Publications, Mineola, NY, USA, 2nd edition, 1999. 

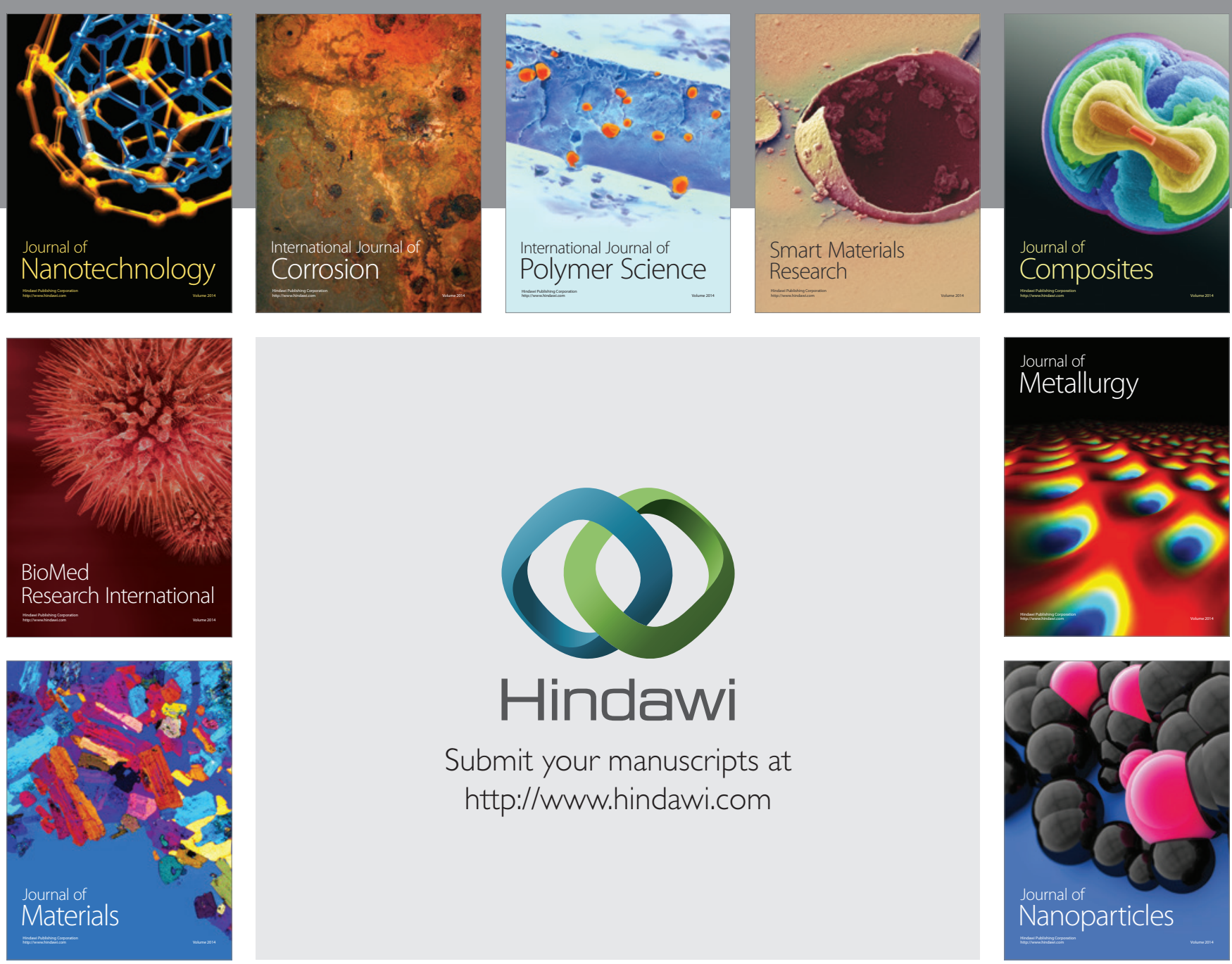

Submit your manuscripts at http://www.hindawi.com
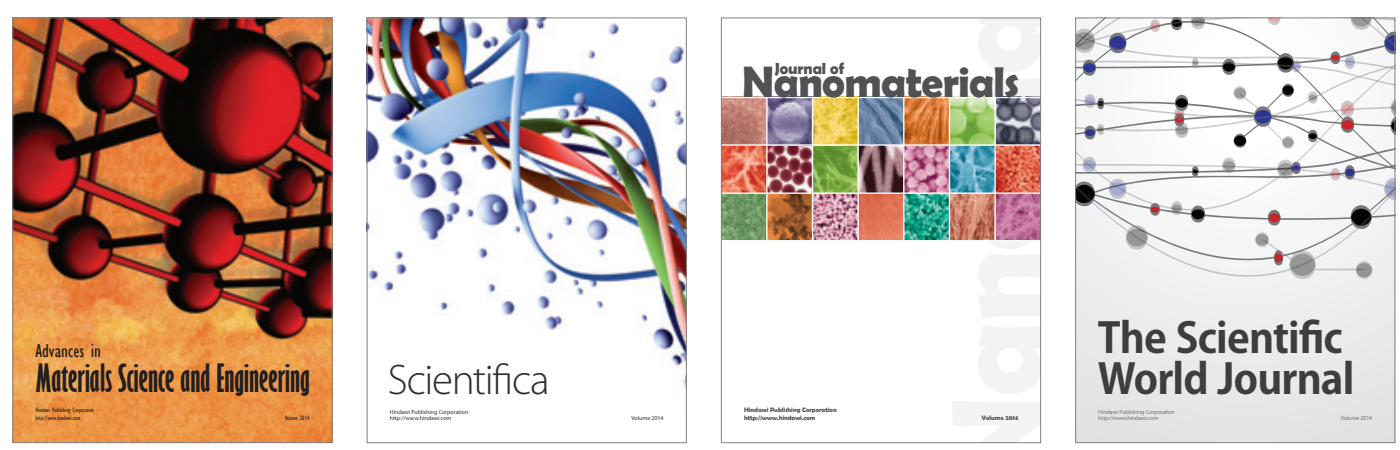

\section{The Scientific World Journal}
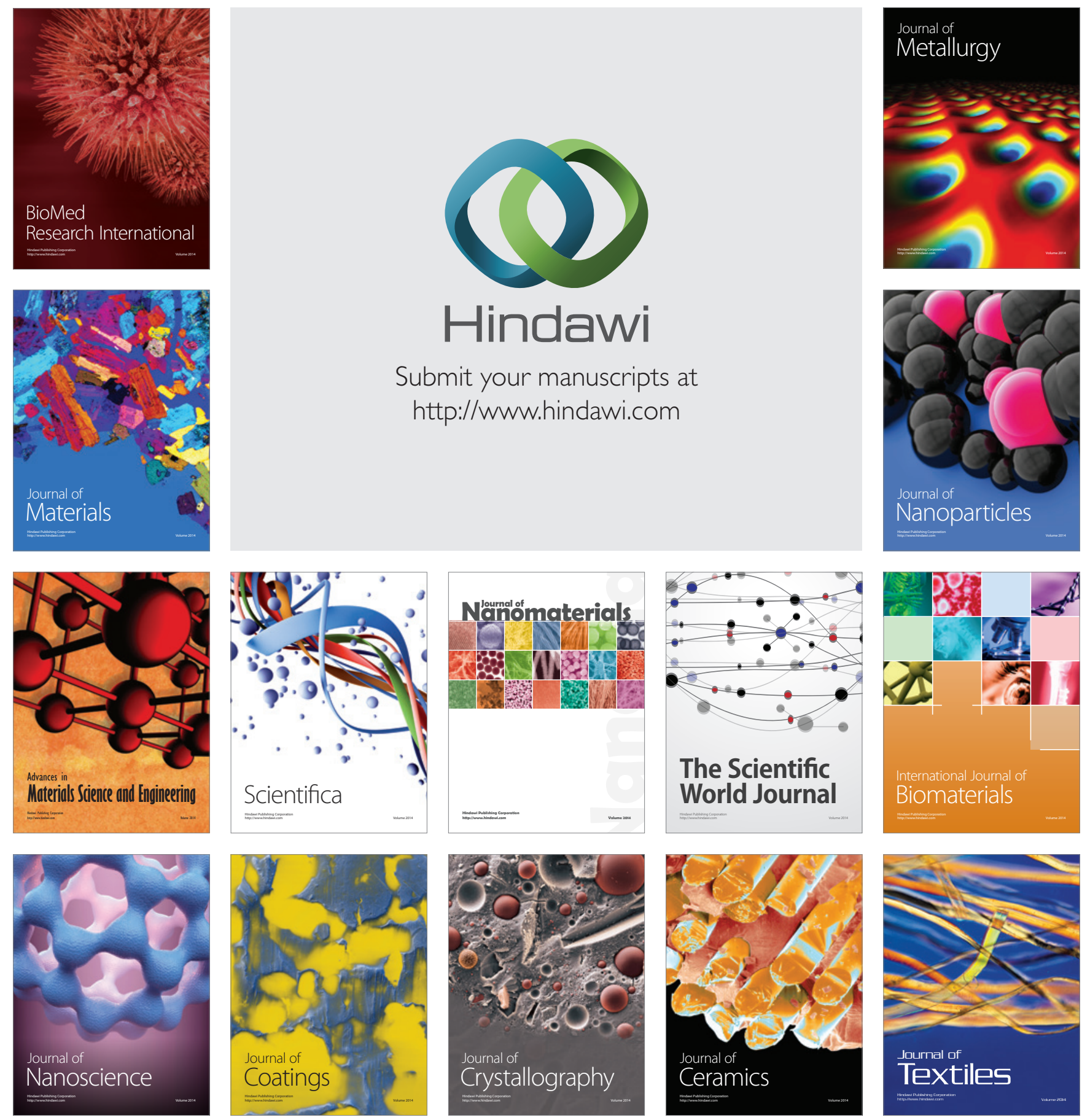